\title{
Modeling Sustainable Supply Chain Management as a Complex Adaptive System: The Emergence of Cooperation
}

\author{
Aida Huerta Barrientos and Idalia Flores de la Mota \\ Additional information is available at the end of the chapter
}

http://dx.doi.org/10.5772/62534

\begin{abstract}
The aim of this chapter is to characterize sustainable supply chain management as a complex adaptive system (CAS) and develop an evolutionary game theory-based model to understand how cooperation emerges from interactions among companies to adopt sustainable management practices. We consider two interacting populations 1 and 2, each one with heterogeneous companies belonging to the same supply chain. One population is expected to behave cooperatively in adopting sustainable management practices while the other is expected to behave uncooperatively. The mathematical model we propose is game-dynamical replicator equations for multiple populations in the prisoner 's dilemma (PD) game and we implement it using NetLogo software. The proportion of cooperative companies in each population that adopt sustainable management practices evolves positively over time as companies only imitate the adoption of sustainable management practices in their own population and in the populations of their partners when the benefit obtained by cooperating is maximum. The spatial patterns observed help us to clarify the preconditions for the emergence of cooperation among companies in managing material, information and capital flows in a sustainable way. Finally, our simulation results show that the sustainable management of supply chains needs to be studied as CASs, in order to take into account the social side of sustainability.
\end{abstract}

Keywords: Sustainable supply chain management, complex adaptive systems, cooperation, modeling and simulation, evolutionary game 


\section{Introduction}

The 2030 Agenda for Sustainable Development of the United Nations [1] is an action plan for people, planet and prosperity that consists of 17 sustainable development goals, namely: 1) no poverty, 2) zero hunger, 3) good health and well-being, 4) inclusive and equitable quality education, 5) gender equality, 6) clean water and sanitation, 7) affordable and clean energy, 8) sustainable economic growth, full and productive employment and decent work for all, 9) building resilient infrastructure, 10) reducing inequality, 11) making cities sustainable, 12) ensuring sustainable consumption and production patterns, 13) taking urgent action to combat climate change, 14) conservation and sustainably use marine resources, 15) protecting, restoring and encouraging the sustainable use of land ecosystems, 16) promoting peace and inclusive societies for sustainable development, and, last but not least, 17) strengthening the means of implementing and revitalizing the Global Partnership for Sustainable Development. Furthermore, in recent years, consumers and legislation have been pressing companies to address the issue of sustainable development in their operations, converting this into an important and challenging task in the new business world $[2,3]$.

The integration of sustainability into supply chains is a critical next step in achieving sustainable development, as supply chains consider the product from the moment when the raw materials are first processed until the product is delivered to the end-user. In this sense, sustainability must ensure issues and flows that extend beyond the core of supply chain management (SCM) [4]. SCM has traditionally been used to describe the planning and control of materials, information flows, and the logistics activities within a company as well as externally among companies [5]. However, the growing interest in SCM has led to numerous definitions being developed to describe it and to some characteristics of sustainability being incorporated into it, for example, the concept of sustainable supply chain management (SSCM). In the last ten years, a number of literature reviews have been published on SSCM [6-8], decision-support tools for SSCM [9, 10], SSCM practices [11, 12] and sustainable supply chain planning [13]. Interesting results are showed in Ref. 6 where a total of 12 definitions for SSCM were identified and its analysis showed that the characteristics of SCM that are most commonly addressed in the definitions were coordination focus and flow focus, while the sustainability characteristics that were explicitly addressed were the three dimensions of the triple bottom line of economic, environmental and social considerations, the stakeholders' focus and the long-term focus of business sustainability. From the systemic perspective, we propose that SSCM is a complex system made up by large numbers of adaptive companies at multiple scales that have adopted sustainable management practices and whose sustainability objectives are based on the three aspects of sustainable development: economic, environmental and social aspects. In this sense, the cooperative management of material, information and capital flows derived from customer and stakeholders' requirements emerges from the interaction among companies that acquire multiple sustainable strategies they need to survive in the greater macro environment.

SSCM research has mainly been qualitative, based on conceptual frameworks and empirical ones, using case studies and surveys [14]. A review of recent SSCM modeling shows that 
researchers have used deterministic approaches and integrated some environmental and sustainability aspects, while neglecting stochastic modeling techniques such as: considering social factors [14], equilibrium models and multi-criteria decision making. All these approaches lead to three main analytical subjects: an analytical hierarchy but without taking into account the social side of sustainability [15], an analytical network process and a life cycle analysis [16]. A hybrid methodology for the modeling and optimization of decision problems in SSCM is presented in Ref. 17. SSCM modeling is a young research area that needs more modeling-based research in order to fully integrate SSCM into business practice. To understand the complex dynamics of SSCM, it is not feasible to apply traditional modeling approaches because they do not take social aspects into account and cannot explain the emergence of cooperation and the dynamic evolution of modern supply chains. So, it is necessary to adopt the complex adaptive system (CAS) approach to achieve a new way of thinking in SCCM research.

CASs are systems where complex behavior emerges as a whole pattern in different scales and as the result of the non-linear interaction of large numbers of simple components, and the system is able to cooperate, adapt, learn and evolve, improving its performance over time. In addition, CASs demonstrate their resilience, their ability to experience external shock and respond to them by recovery and adaptation. In this sense, modern SCM is a collectively selfsustaining structure of functions and obligations that lives in a socio-economic-environmental world, exchanges signals, and survives or dies. CASs are distinguished by the extensive use of computer simulation as a research tool. Several scholars have studied supply chain problems based on a CAS approach and obtained results from their research [18-21]. In this chapter we present a study concerning the modeling of SSCM as a CAS. The aim of this chapter is to develop an evolutionary game theory-based model of SSCM to understand how cooperation emerges from interactions among companies in a supply chain in order to adopt sustainable management practices, taking into account the social side of sustainability. We propose gamedynamical replicator equations for multiple populations in the PD game for the mathematical model and implement it using NetLogo software. We find that sustainable management of supply chains based on a CAS approach really appreciates the interactions among companies in supply chains and the complex dynamics that they create, which can enhance the resilience of the SSCM as a whole when responding to the complex environment.

This chapter is organized as follows. We begin by reviewing the characteristics of a resilient SSCM in Section 2. The top-down and bottom-up modeling approaches and decision making in SSCM are presented in Section 3. We develop and implement the game-dynamical replicator equations for multiple populations in the PD game as the simulation model of SSCM using NetLogo software and then we analyze how cooperation emerges from interactions among companies in a supply chain to adopt sustainable management practices, in Section 4. Based on the simulation results, some proposals for sustainable, adaptive and cooperative management of supply chains are outlined in Section 5 and we give our conclusions in Section 6. 


\section{Toward a resilient SSCM}

From the systemic perspective, the best ways for the SSCM to face future global challenges characterized by unpredictable socio-ecological-economic situations are by having the flexibility, through its systemic resilience, to adapt to new situations, absorb shocks and recover quickly.

\subsection{Systemic resilience}

In the past few years, resilience has been used significantly for governing and managing a transition toward sustainability [22]. As suggested by Walker and Salt [23], the key to ensuring a sustainable and resilient supply of the essential ecosystem services on which humanity depends on is by enhancing the resilience of socio-ecological systems, instead of optimizing isolated components of the system. So, in SSCM, diverse components such as companies, suppliers, stakeholders and consumers provide different options for responding to change and dealing with the uncertainty and the unforeseen caused by interactions with its complex environment, but the SSCM needs to respond in a coordinated and collaborative way. According to Carpenter et al. [24], systemic resilience has three defining characteristics that, when applied to SSCM, are as follows:

1. The amount of change a SSCM can experience and still remain within the same domain of attraction.

2. The degree to which SSCM is capable of self-organization.

3. The degree to which SSCM can build the capacity to learn and to adapt.

A SSCM is a network of many actors such as consumers, providers, producers, etc. that interact in parallel through the interchange of material, information and capital flows. From their interactions arise global patterns of self-organization that to some degree will enable the SSCM to be resilient due to the structure. It is important to note that the degree of self-organization of the SSCM's companies is variable, unpredictable and an individual understanding of each particular consumer, provider or producer would not have been made it possible to predict it.

One tool for enhancing the resilience of SSCM could be adaptive management, increasing the collective capacity of stakeholders and companies of a SC to learn and adapt in a sustainable development context. The diversity of the components in the SSCM also permits them to compensate for the loss or failure of others by redundancy in their material, information and capital flows. Participation through the active engagement of all the relevant stakeholders of SC is considered fundamental for building the relationships needed to improve socioecological-economic resilience. As suggested in Ref. 25, collaboration, as a requirement for implementing sustainable management approaches, may contribute to inter-organizational dynamics by strengthening the knowledge absorption capacity, structuring solutions, and motivating activity around a commonly defined goal such as the sustainability of supply chains. 


\subsection{Modularization}

The complexity of a SSCM is derived from the interchange of material, information and capital flows among companies that have adopted sustainable management practices in a complex environment. If there are a lot of strong interactions as a result of globalization and technological change, then the SSCM becomes vulnerable due to the presence of undesired cascade and side-effects. This means that the SSCM would not be able to recover well from disruptions and, in consequence, will not be sufficiently resilient to survive. In order to avoid a catastrophic situation and, following recommendations for a well-designed system, the SSCM needs to be designed in a hierarchical way of functional modules or units, taking into account dynamic and adaptive decoupling strategies between these modules to minimize the level of connectivity in order to prevent a cascade effect. Additionally, the interactions among companies could be modified as much as necessary to let new outcomes emerge such as, for example, cooperation among companies. In order to reduce the impact of dysfunctional links on the hierarchical structure of the SSCM, redundant interactions among companies and stakeholders with a lower level of connectivity need to be implemented. This means that one strategy to be implemented by the SSCM in order to survive being resilient is for it to operate in a modular way with a low level of connection between modules. In the next section, we present the topdown and bottom-up modeling approaches and decision making in SSCM to understand how the emergence of resilience of a SSCM from interrelations among companies can be modeled.

\section{Top-down versus bottom-up decision making and modeling approaches}

On the one hand, when studying CASs, it is necessary to develop models that represent the real system through abstractions of the aspects of interest based on macro and micro perspectives. For this, we start to develop a system model from a top-down perspective that considers the system as a whole at macro level. Then, when the bottom is reached, the bottom-up deduction is used but guided by the top-down view, at micro level. On the other hand, the decision-making process in the SSCM has been traditionally based on the top-down approach. It means that leader companies exert their command and control power in a centralized way but limiting the adaptation of local companies and canceling the collective intelligence of the SSCM. This traditional decision-making process is not sufficient for modern SSCM, which is characterized by unpredictable situations that demand the adaptation and learning of local companies.

\subsection{Top-down approach}

In order to model a real CAS, it is necessary to observe the system structures at macro level. The top-down approach is a holistic perspective provided by synthetic microanalysis, in which experiments are performed to find natural emergent properties and delineate macroscopic phenomena with systemic concepts [26]. It represents the first approximation to the real system. Top-down decision making (see Figure 1) works very well in SSCMs that are simple 
and deterministic, not complex. In this case, the SSCM can be considered predictable, with low variability and centralized control, so its performance can be enhanced. At macro level, the decision time is more important than the consensus between the constituent parts. A SSCM that is controlled from the top-down is vulnerable due to the concentration of power that makes it easily corruptible [27] in the exchange of information, material and capital. So, the top-down approach needs to be complemented by the bottom-up approach in order to enhance the resilience in a SSCM for increasing the collective capacity of companies and stakeholders to learn and adapt in a sustainable development context.
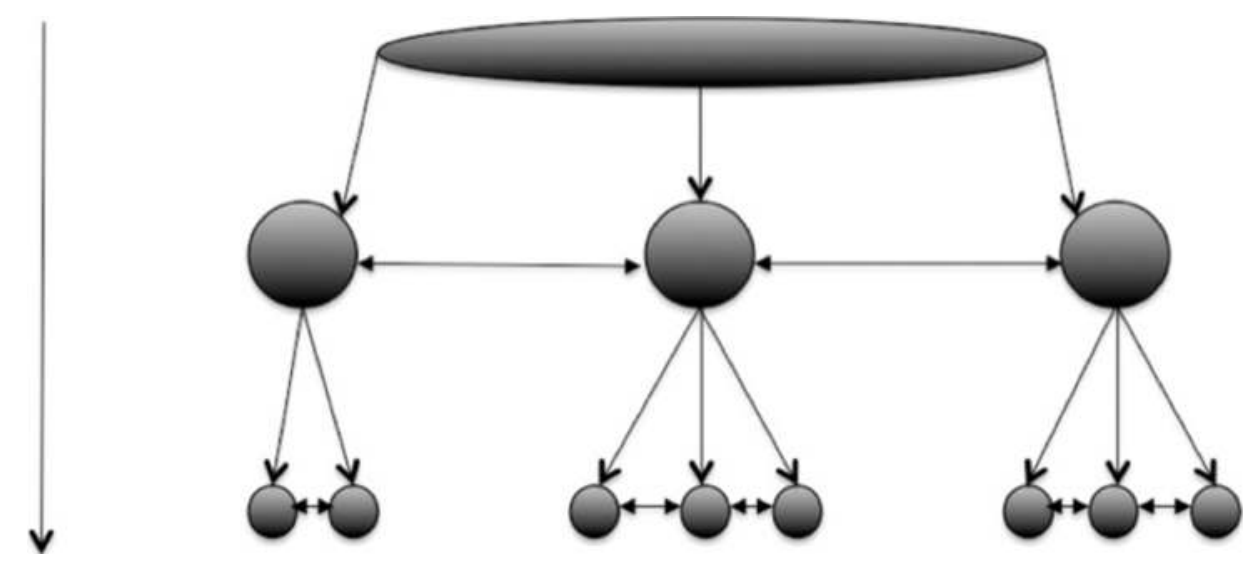

Figure 1. Diagram of the top-down approach, the flow of information, materials and capital is represented by arrows.

\subsection{Bottom-up approach}

Once the system structures have been observed based on the top-down perspective and the bottom has been reached, we need to analyze them in terms of the laws of their constituent parts combined with suitable idealization and approximation [26] at the micro level. The bottom-up approach is a deductive perspective, in which experiments are performed to find natural emergent properties at certain levels as a result of the interactions between the constituent parts.

Bottom-up decision making (see Figure 2) works very well in SSCM with coordination mechanisms that support flexibility, local adaptations, creativity and diversity. In this case, the power is decentralized, and both the companies and stakeholders in the SSCM are empowered and self-organized according to their interrelations, based on their own sustainability objectives, enabling the sustainable collective intelligence to be more resilient. 

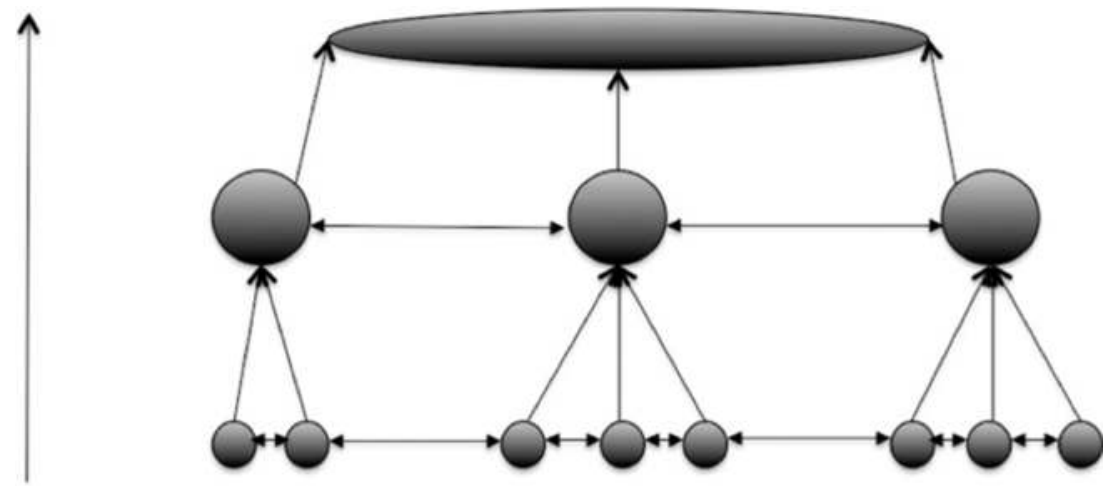

Figure 2. Diagram of bottom-up approach, the flow of information, materials and capital is represented by arrows.

\subsection{Synthetic microanalysis}

Synthetic microanalysis (see Figure 3) still combines the top-down and bottom-up perspectives, uniting without reducing. Based on synthetic microanalysis, system and constituents' views, each confirmed by experiments, we are able to find out about the approximations, idealizations, and possible contingent factors required for connecting them [26]. The main purpose of synthetic microanalysis is to use the net of macro concepts to obtain the feedback of the micro information relevant to the explanation of system's emergent properties.
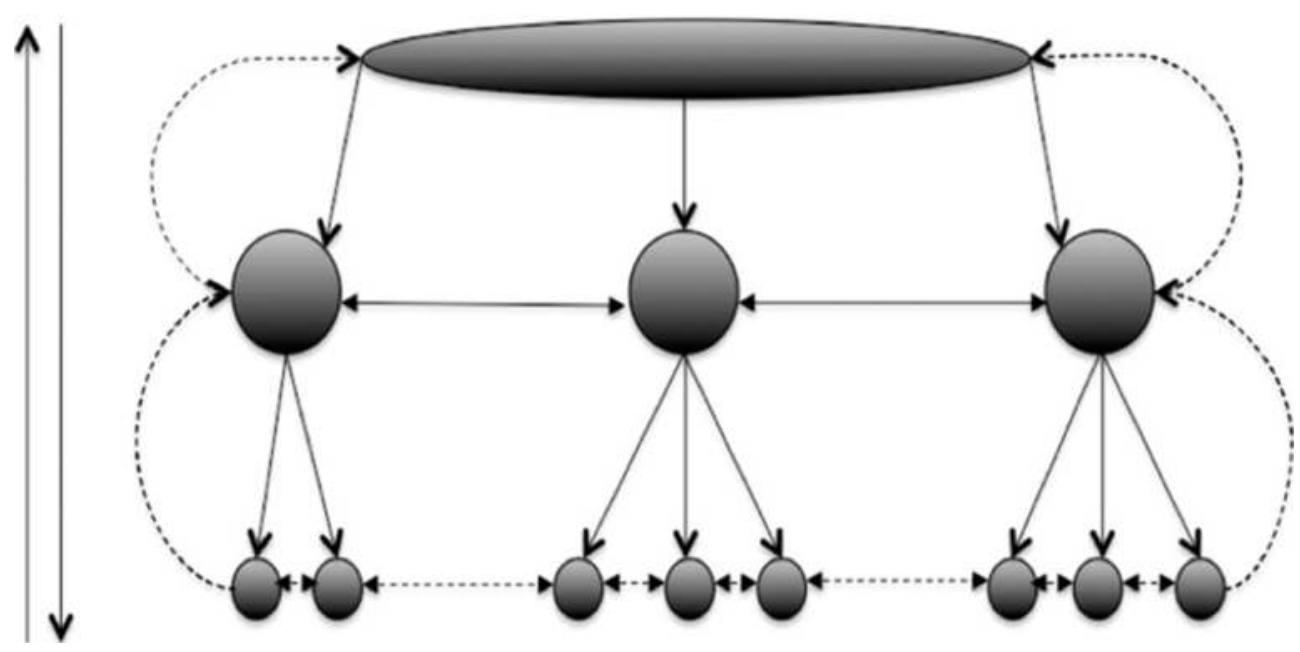

Figure 3. Diagram of synthetic microanalysis. 
In the next section, we propose game-dynamical replicator equations for multiple populations in the PD game as the SSCM model, using the bottom-up approach. Then we implement it in a computer using NetLogo software. From the computer simulation results, we analyze how cooperation emerges from interactions among companies in a supply chain for the adoption of sustainable management practices that could, in some sense, favor the resilience of the SSCM.

\section{Modeling and simulation of SSCM as a CAS at the level of companies}

By modeling the SSCM as a CAS, we can study its ability to reorganize its constituent adaptive companies at multiple scales so that it can face the problems posed by its macro environment. In a world of selfish companies, from their interactions, cooperation could emerge as a way of achieving sustainability in their management. We observe that, in the literature, in order to gain a better understanding of factors promoting cooperation among individuals, biologists, economists, social scientists, mathematicians and physicists have intensively studied game theoretical problems such as Prisioner's dilema game, snowdrift game, and public goods game [28].

Game theory was developed by John von Neumann in 1928 and discussed in Ref. 29 as a theory of "games of strategy" to provide a new approach to a number of economic questions. Game theory assumes that a fraction of people known as cooperators interacts with another fraction known as non-cooperators. Therefore, a large amount of research has focused on how cooperation can be supported by mechanisms such as repeated interactions; reputation; clusters of cooperative individuals; costly punishment; success-driven migration [30, 31]. But, the problem of cooperation among groups with different preferences such as the SSCM (e.g. suppliers, manufacturers and retailers with different sustainable goals in the three dimensions: economic, environmental and social) is a young research area that needs attention.

For example, in a SSCM, suppliers and manufacturers appear to practice different sustainable management but they interact with each other on a daily basis interchanging material, information and capital flows, not necessarily in a sustainable way. In this sense, it is important to see whether it is possible to identify preconditions for cooperation among companies that belong to the same supply chain, in order to adopt sustainable management practices without being controlled by a central authority. To answer this research question, we model cooperation in an evolutionary game-theoretical way. Evolutionary game theory goes back to John Maynard Smith [32, 33] who adopted the methods proposed by von Neumann to the context of biological natural selection. Evolutionary game theory studies the strategies of populations of agents who repeatedly engage in strategic interactions. The evolution of behavior of populations is represented by the so-called replicator dynamic introduced by Taylor and Jonker [34, 35]. In this situation, when two populations characterized by the "strategies" or "behaviors" $i$ and $j$ states interact with each other, game theory formalizes the 
result according to payoffs $P_{i j}$ and the structure of the payoff matrix $\left(P_{i j}\right)$ determines the kind of game [36].

According to Helbing and Lozano [36], the replicator equation is as follows:

$$
\frac{d p(i, t)}{d t}=p(i, t)\left[\sum_{j} P_{i j} p(j, t)-\sum_{j, l} p(l, t) P_{l j} p(j, t)\right]
$$

where the relative frequency of behavior $i$ of populations is represented by $p(i, t)$, which increases when the expected success $F_{i}=\sum_{j} P_{i j} p(j, t)$ exceeds the average, $\sum_{i} F_{i} p(i, t)$.

\subsection{The model}

In this study, we consider the PD game that is an abstract formulation of some very common and very interesting situations [30], in which what is best for each company individually leads to mutual defection, when every company would have been better off with mutual cooperation. We propose game-dynamical replicator equations for multiple populations to describe the evolution in time of the proportions $p(t)$ and $q(t)$ of cooperative companies in populations 1 and 2 of the same supply chain. In the model, we assume that companies in population 1 prefer to adopt sustainable management practices in their operations while companies in population 2 operate based on unsustainable management practices, but the companies of populations 1 and 2 interact in a daily basis interchanging material, information and capital flows. Our study is carried out for $2 * 2$ game, which contains four payoffs: $\mathrm{T}$ (temptation) to behave noncooperative, $\mathrm{R}$ (reward) for mutual cooperation, $\mathrm{P}$ (punishment) for mutual noncooperative behavior and S (Sucker's payoff) for a cooperative individual meeting an uncooperative one.

According to Helbing et al [37], the game-dynamical replicator equations for two populations are as follows:

$$
\begin{aligned}
& \frac{d p(t)}{d t}=p(t)[1-p(t)] F(p(t), q(t)) \\
& \frac{d q(t)}{d t}=q(t)[1-q(t)] G(p(t), q(t))
\end{aligned}
$$

where the functions $F(p(t), q(t))$ and $G(p(t), q(t))$ reflect the interactions among companies in and out of populations 1 and 2, respectively.

In this study, the model was developed using agent-based modeling methodology and implemented using NetLogo software. This software is still the most widely used agent-based 
modeling language [38]. The agents represent the companies and they are grouped in two populations according to whether or not they prefer to adopt sustainable management practices. We propose six parameters in the model: the number of groups of companies in the supply chain (NG), the number of companies in each group (NC), the cost (C) and the benefit (B) of cooperation in adopting sustainable management practices. Companies only derive benefit if other companies in their group cooperate, and companies always pay the cost of cooperating with others in adopting sustainable management practices because they need to implement them in their daily operations. The probability of one company that has adopted sustainable management meeting another company in the same situation $\left(\mathrm{P}_{\mathrm{a}}\right)$ and the probability of one company that has adopted sustainable management in their operations meeting another company that has not adopted it yet $\left(\mathrm{P}_{\mathrm{b}}\right)$, as showed in Table $\mathbf{1}$.

\begin{tabular}{|c|c|c|}
\hline Parameter & Minimum & Maximum \\
\hline Groups of companies in the supply chain (NG) & 10 & 50 \\
\hline Companies in each group (NC) & 10 & 20 \\
\hline $\begin{array}{l}\text { Cost }(C) \text { of cooperation in adopting sustainable } \\
\text { management practices }\end{array}$ & 1 & 5 \\
\hline $\begin{array}{l}\text { Benefit (B) of cooperation in adopting sustainable } \\
\text { management practices }\end{array}$ & 1 & 10 \\
\hline $\begin{array}{l}\text { Probability of one company that has adopted sustainable } \\
\text { management meeting another company } \\
\text { in the same situation }\left(\mathrm{P}_{\mathrm{a}}\right)\end{array}$ & $50 \%$ & $100 \%$ \\
\hline $\begin{array}{l}\text { Probability of one company that has adopted sustainable } \\
\text { management in their operations meeting another company } \\
\text { that has not yet adopted it }\left(\mathrm{P}_{\mathrm{b}}\right)\end{array}$ & $50 \%$ & $100 \%$ \\
\hline
\end{tabular}

Table 1. Parameters for simulating the interaction among companies in adopting sustainable management practices

We ran the computer simulation in NetLogo software in 50 steps considering the variation of the six parameters, $\mathrm{NG}, \mathrm{NC}, \mathrm{C}, \mathrm{B}, \mathrm{P}_{\mathrm{A}}$ and $\mathrm{P}_{\mathrm{B}}$ listed in Table 1, to find out under what conditions cooperation in adopting sustainable management practices emerges in a supply chain, given that companies are self-interested. We proposed four simulation scenarios so we ran each one in 50 time steps. In this sense, the simulation run finishes when the 50 time steps are achieved. The computer simulation results are presented and analyzed in Sections 4.2 and 4.3.

\subsection{Results}

In the first simulation scenario, we fixed the $\mathrm{B}, \mathrm{C}, \mathrm{P}_{\mathrm{a}}$ and $\mathrm{P}_{\mathrm{b}}$ parameters in their minimum values while the NG and NC parameters varied between their minimum and maximum values. The evolution of dynamics in the timeline is showed in Figures 4 and 5. 

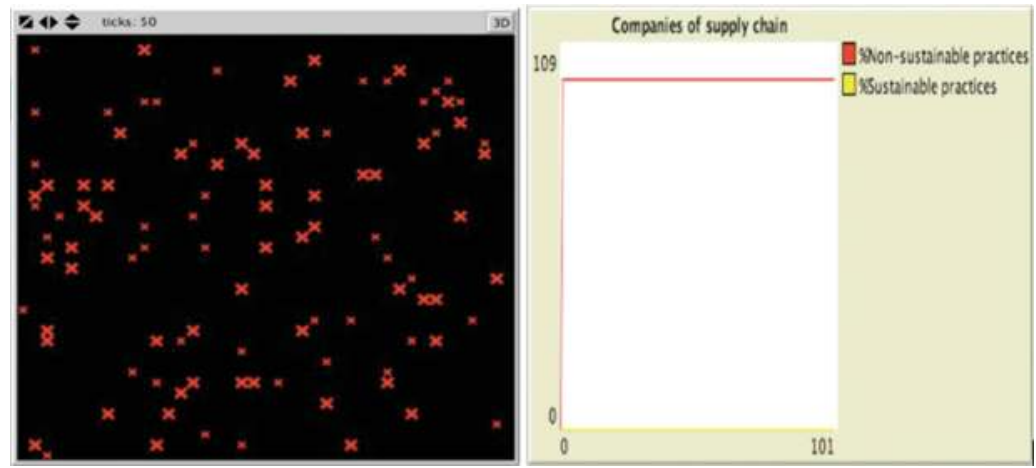

Figure 4. Snapshot of the computer simulation, showing the representative dynamics of the interactions among the companies in a supply chain in respect of adopting sustainable management practices updated on a $20 \times 20$ lattice for NG and NC minimum (100 companies).

In Figure 4, we observe that the effect of 10 groups and 10 companies in each group on the interactions between the companies that have adopted sustainable practices and those that have not yet adopted them is that in the long term all the companies decide not to adopt sustainable practices. In this case, the cost and benefit of cooperation in adopting sustainable practices remains unchanged, at its minimum value.
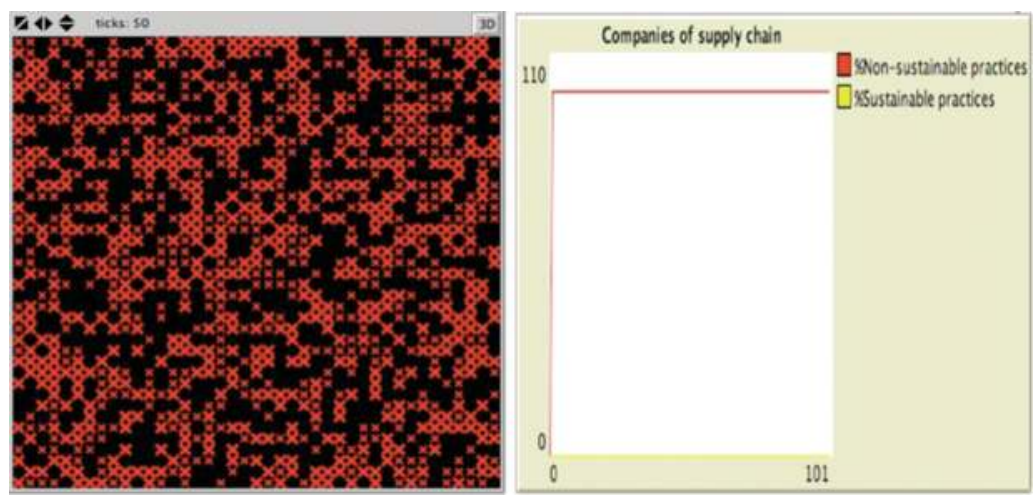

Figure 5. Snapshot of the computer simulation, showing the representative dynamics of interactions among companies in supply chain in respect of adopting sustainable management practices updated on a $20 \times 20$ lattice for NG and NC minimum (100 companies).

In Figure 5, we observe that the effect of 50 groups and 20 companies in each group on the interactions between the companies that have adopted sustainable practices and those that have not yet adopted them is that in the long term all the companies decide not to adopt sustainable practices, as in the case showed in Figure 4. In this case, the cost and benefit of cooperation in adopting sustainable practices remain unchanged, at its minimum value. 
In the second simulation scenario, we fixed the B, C, NG and NC parameters at their minimum value while the $P_{a}$ and $P_{b}$ parameters were varied to its maximum value. The evolution of dynamics in the timeline is showed in Figures 6 and 7.
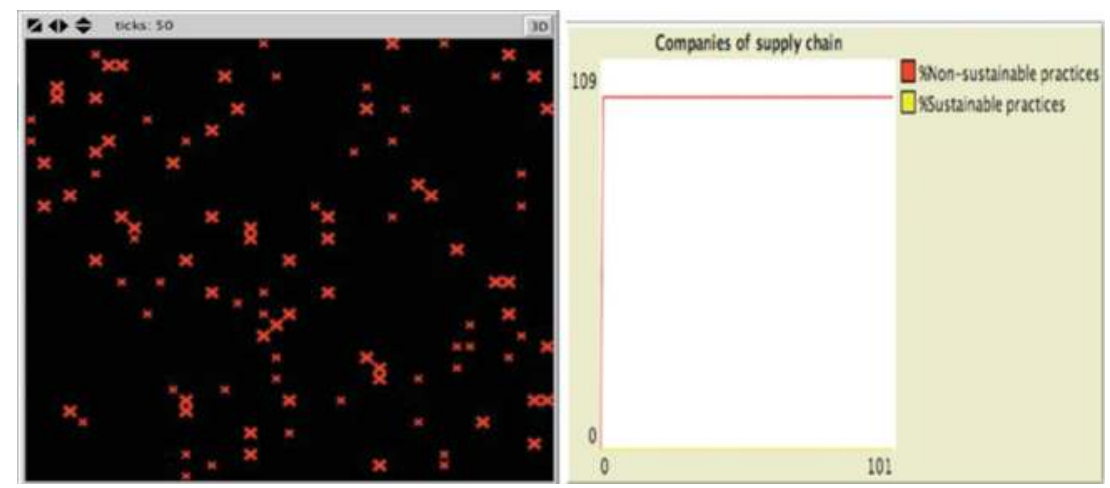

Figure 6. Snapshot of the computer simulation, showing the representative dynamics of the interactions among the companies in a supply chain in respect of adopting sustainable management practices updating on a $20 \mathrm{X} 20$ lattice for $\mathrm{P}_{\mathrm{a}}$ maximum and $\mathrm{P}_{\mathrm{b}}$ minimum (100 companies).

In Figure 6, we observe that the effect of the probabilities of one company that has adopted sustainable management meeting another company in the same situation (50\%) or meeting another that has not adopted it (50\%) on the interactions between all the companies is that, in the long term, all the companies decide not to adopt sustainable practices. In this case, the cost and benefit of cooperation in adopting sustainable practices as well as the size of groups of companies remain unchanged, at its minimum value.
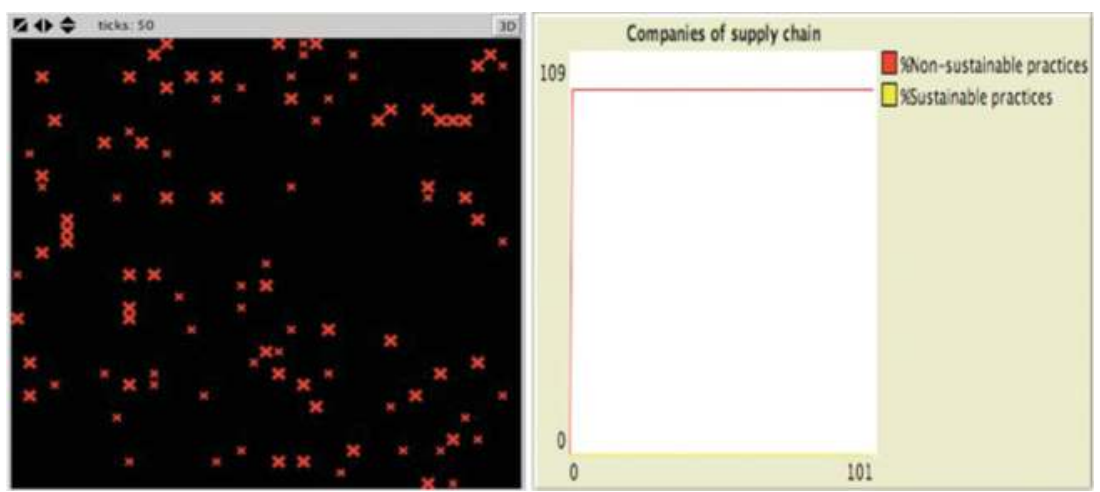

Figure 7. Snapshot of the computer simulation, showing the representative dynamics of interactions among companies in supply chain in respect of adopting sustainable management practices updating on a $20 \times 20$ lattice for $P_{a}$ minimum and $\mathrm{P}_{\mathrm{b}}$ maximum (100 companies). 
In Figure 7, we observe that the effect of the probabilities of one company that has adopted sustainable management meeting another company in the same situation $(100 \%)$ or meeting another that has not adopted it $(100 \%)$ on the interactions between all the companies is that in the long term all the companies decide not to adopt sustainable practices. In this case, the cost and benefit of cooperation in adopting sustainable practices as well as the size of groups of companies remain unchanged, at its minimum value as showed in Figure 6.

In the third simulation scenario, we fixed the $C, N G, N C, P_{a}$ and $P_{b}$ parameters at their minimum values while the $B$ parameter was set up to its maximum value. The evolution of dynamics in the timeline is showed in Figure 8.
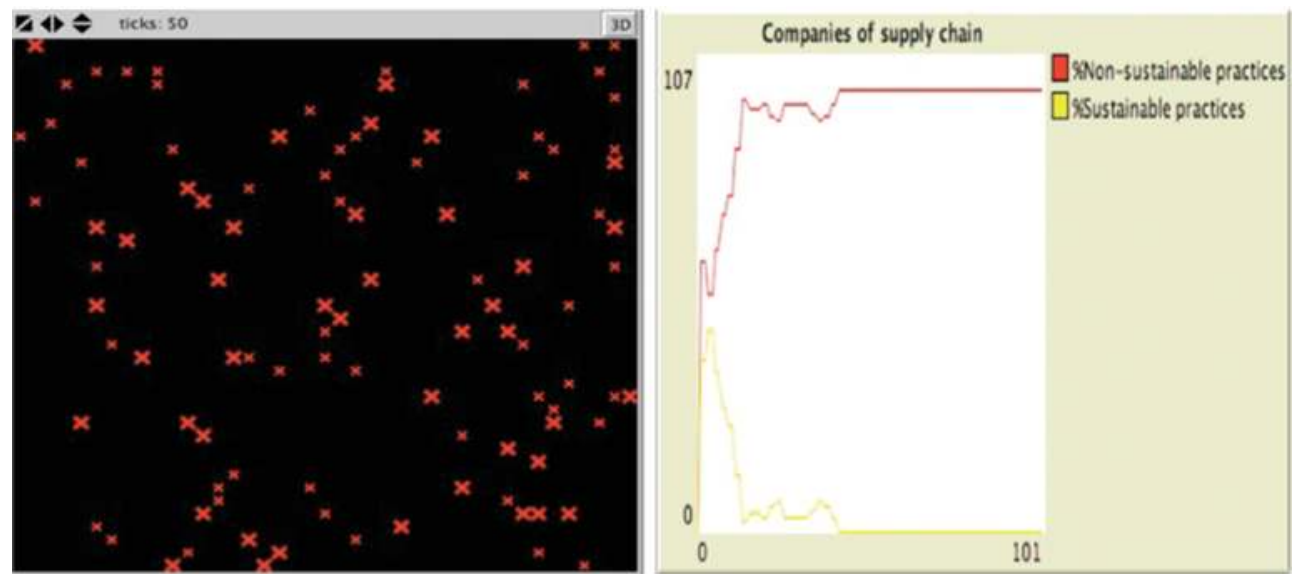

Figure 8. Snapshot of the computer simulation, showing the representative dynamics of interactions among companies in supply chain in respect of adopting sustainable management practices updating on a $20 \times 20$ lattice for B maximum value and $C, N G, N C, P_{a}$ and $P_{b}$ parameters in its minimum value (100 companies).

In Figure 8, we observe that the effect of the benefits of adopting sustainable practices at their maximum value on the interactions between all the companies is that in the short term all the companies decide to adopt sustainable practices but in the long term they decide to cancel the adoption of the said practices. In this case, the cost, the size of groups, and the probabilities of interacting with other companies in the same situation remain unchanged, at their minimum value.

Finally, in the fourth simulation scenario we fixed the C, NG, NC and $\mathrm{P}_{\mathrm{b}}$ parameters at their minimum value, while the $B$ and $P_{a}$ parameters were set up at their maximum value. The evolution of dynamics in the timeline is showed in Figure 9. 

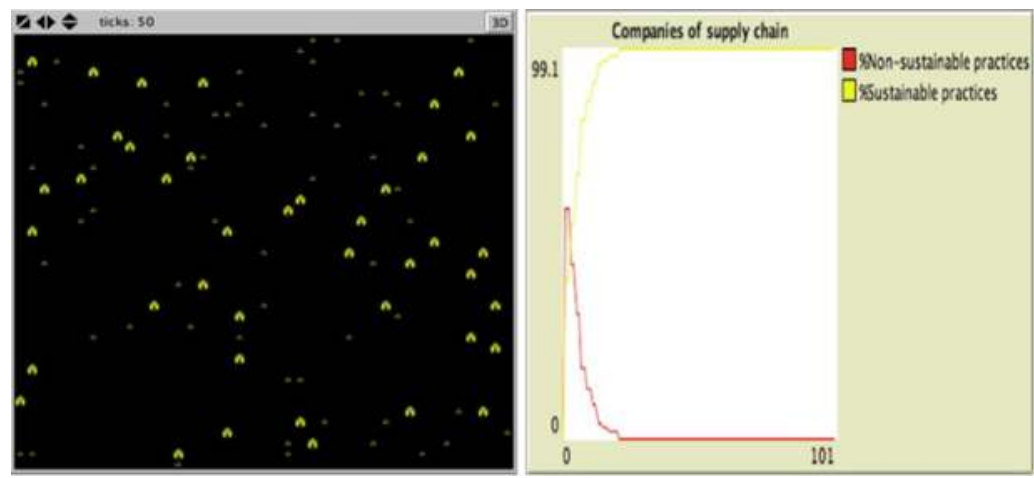

Figure 9. Snapshot of the computer simulation, showing the representative dynamics of interactions among companies in supply chain in respect of adopting sustainable management practices updating on a $20 \times 20$ lattice for $B$ and $P_{a}$ parameters in its maximum value while $\mathrm{C}, \mathrm{NG}, \mathrm{NC}$ and $\mathrm{P}_{\mathrm{b}}$ parameters in its minimum value (100 companies).

In Figure 9, we observe that the effect in adopting sustainable practices at its maximum value and the probability of companies that have adopted sustainable practices meeting another company in the same situation at $100 \%$ on the interactions between all the companies is that in the short term, in fact immediately they start to interact, all the companies decide to adopt sustainable practices. In the long term, they do not change their decision. In this case, the cost, the size of groups and the probabilities of interacting with other companies in the same situation remain unchanged, at their minimum value.

\subsection{The challenge of cooperation among companies in adopting sustainable management practices}

From the simulation results, we observe that the proportion of cooperative companies of each population adopting sustainable management practices evolves positively in time as companies imitate the adoption of sustainable management practices in their own population and in the populations of their partners just when the benefits are maximum, as showed in the fourth scenario. In this sense, two preconditions are necessary for companies in a supply chain to cooperate in adopting sustainable management practices, as follows:

1. Interaction with companies that have adopted these kinds of practices in their operations and management.

2. Explicit knowledge of the benefits of operating in a sustainable way.

For the first point, companies are responsible for looking for partners that have a good reputation for practicing sustainable management in a supply chain, technology can help them. This precondition operates in the bottom-up decision-making approach. For the second point, associations, institutions as well as governments need to enhance the benefits of adopting sustainable management practices in order to be attractive for companies. This precondition operates in the top-down decision-making approach. It is clear that companies will not adopt sustainable practices by just interacting with companies that operate in a sustainable way, by 
incrementing the size of a group of partners or by dismissing the cost of sustainable operation, as showed in the first, second and third scenarios. Based on our results, in the next section we give some proposals for the sustainable, adaptive and cooperative management of supply chains.

\section{How to manage supply chains in sustainable, adaptive and cooperative way: some proposals}

The sustainable management of a supply chain requires companies that are able to adapt to new interactions with others companies, maximizing the benefits of managing the material, information and capital flows in a sustainable way. Here, we propose some actions that, from our simulation results, we consider could enhance the sustainable management of supply chains:

1. Improving resilience in SSCM.

2. Building a reputation among companies in promoting sustainable management practices.

3. Balancing top-down and bottom-up decision making in supply chains.

4. Using information systems (ISs) to compensate best sustainable management practices.

5. Giving people cooperative and adaptive management skills.

\subsection{Improving resilience in SSCM}

Stakeholders and companies must increase their ability to learn to adapt in a sustainable development context. The cooperation and participation through the active engagement of all relevant stakeholders of SC are considered fundamental to building the relationships needed to improve socio-ecological-economic resilience through interactions that maximize the benefit for companies in terms of sustainability. On the one hand, if a SSCM is controlled from the top-down, then it will become vulnerable and, in consequence, the concentration of power in companies will make them easily corruptible. On the other hand, as our simulation results show, cooperation in the sustainable management of material, information and capital flows emerges from the bottom-up as a result of self-organization among companies that perceive the benefits of interacting with companies that have adopted sustainability practices. In this case, the structure of the SSCM is adjusted by the emergent interrelations enabling the SSCM to face an unpredictable environment.

\subsection{Building a reputation in SSCM to promote the adoption of sustainable management practices}

The companies in a SC need to build its reputation of their own business based on multiple sustainability criteria in the three aspects of sustainable development, i.e., economic, environmental and social aspects. Green innovations [39] as well as reputation can advantage the 
formation of new interactions between companies that have adopted sustainable management practices in their business and other companies that have not yet adopted such practices. On the one hand, based on our simulation results, we observed that companies only imitate the adoption of sustainable management practices in their own population and in the populations of their partners when the benefits are maximum and when they interact with others that have adopted these practices. On the other hand, indirect reciprocity [40] give and you shall receive is built on reputation and can sustain high levels of cooperation [41] for adopting sustainable practices. In this sense we propose that building a reputation for practicing sustainability principles can be a path for other companies to follow. So, government and institutions need to recognize and increase the benefits for prestigious companies in adopting the best sustainability principles and practices as their strategy, in order to contribute to their motivation for maintaining their reputation as contributors for local and global sustainable development.

\subsection{Top-down and bottom-up decision making in SSCM}

As discussed in Section 3, the top-down approach needs to be complemented by the bottomup approach in order to enhance the resilience in a SSCM for increasing the collective capacity of companies and stakeholders to learn and adapt in a sustainable development context.

\subsection{Using information systems to compensate best sustainable management practices}

As was demonstrated in our simulation results, the cooperation of companies in the adoption of sustainable management practices is a function of the benefits perceived by them. In this direction, a system of benefits supported by the IS needs to be developed.

It is important for administrators in the supply chain to understand the importance of sustainability, and how objectives can be brought into line to achieve these goals by using information technologies (ITs). They also need to know the difference between using ISs and ITs and how they can be adapted to achieve sustainability.

Using what is known as green IT and green IS has these main differences:

1. An IT transmits, processes, or stores information.

2. An IS is an integrated and cooperating set of software using ITs to support individual, group, organizational, or societal goals.

Green IT is mainly focused on energy efficiency and equipment utilization. It addresses issues such as

1. Designing energy efficient chips and disk drives.

2. Replacing personal computers with energy efficient thin clients.

3. Use of virtualization software to run multiple operating systems on one server.

4. Reducing the energy consumption of data centers.

5. Using renewable energy sources to power data centers. 
6. Reducing electronic waste from obsolete computing equipment.

7. Promoting telecommuting and remote computer administration to reduce transportation emissions.

According to Watson et al [42], the use of IS refers to the design and implementation of ISs that contribute to sustainable business processes. This helps an organization to

1. Reduce transportation costs with a fleet management system and dynamic routing of vehicles to avoid traffic congestion and minimize energy consumption.

2. Support team work and meetings when employees are distributed throughout the world, and thus reduce the impact of air travel. IS can move remote working beyond telecommuting to include systems that support collaboration, group document management, cooperative knowledge management, and so forth.

3. Track environmental information (such as toxicity, energy used, water used, etc.) about the creation of products, their components, and the fulfillment of services.

4. Monitor a firm's operational emissions and waste products to manage them more effectively.

5. Provides information to consumers so that they can make green choices more conveniently and effectively.

Green IS has a greater potential than green IT because it tackles a much larger problem. It can make entire systems more sustainable compared to reducing the energy required to operate ITs.

Other authors give a definition of IS and again they focus the importance of it. For example, in the Melville's [43] study, it can be seen that: We thus define IS for environmental sustainability as IS-enabled organizational practices and processes that improve environmental and economic performance. We launch a new discourse on IS innovation for environmental sustainability by drawing upon the uniqueness of IS scholarship, which incorporates both behavioral science (search for truth) and design science (search for utility in designed artifacts) (Hevner et al. [44]). Finally, it is important to mention that IS is used in different ways depending on how the problem is framed. For example, if the problem is framed in economic terms, then IS may be viewed as a means by which energy productivity (quotient of output and amount of energy used) is increased. If the problem is viewed in ecological terms, then IS might be framed in terms of how online social networking reduces greenhouse gas emissions or how data centers increase greenhouse gas emissions. Another implication of complexity is the need for research methodologies that account for uncertainty and feedback, such as system dynamics by Sterman [45]. Altogether, the environmental sustainability research context is distinctive in scope, complexity, and urgency, requiring IS researchers to extend epistemological horizons [43]. 


\subsection{Giving people cooperative and adaptive management skills}

Problems involving ISs and environmental sustainability involve human behavior and the broader social, organizational, and environmental contexts. Review of the IS and operation literature and examination of other business literature reveal three classes of sustainability phenomena: (1) how cognitive states about sustainability (beliefs, opportunities, etc.) emerge; (2) actions of organizations and individuals regarding sustainability practices and processes; and (3) environmental and financial performance outcomes. Taken together, the three classes of phenomena comprise micro and macro issues. Coleman's [46] model of micro-macro relations provides the foundation for a conceptual framework, developed by Melville [43]. This framework called Belief-Action-Outcome (BAO) is summarized in Figure 10, and is explained in Table 2.

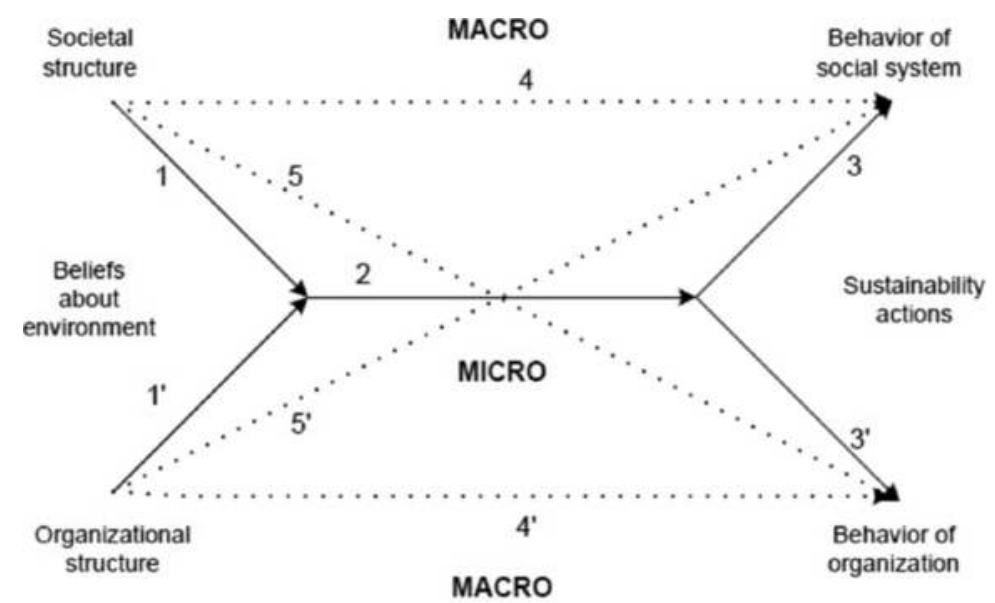

Figure 10. BAO framework for IS research and sustainability. Source: Ref. 43.

\begin{tabular}{|c|c|c|c|}
\hline & Belief formations & Action formation & Outcome \\
\hline Description & $\begin{array}{l}\text { How psychic states (beliefs, desires, } \\
\text { opportunities, etc.) about the natural } \\
\text { environment are formed. }\end{array}$ & $\begin{array}{l}\text { How psychic states about } \\
\text { the natural environment } \\
\text { translate to actions. }\end{array}$ & $\begin{array}{l}\text { How sustainability actions affect social } \\
\text { and organizational systems. How } \\
\text { macro states affect behavior of society } \\
\text { and organizations. }\end{array}$ \\
\hline $\begin{array}{l}\text { Analysis } \\
\text { level }\end{array}$ & Macro-micro & Micro-micro & $\begin{array}{l}\text { Micro-macro (links } 3 \text { and } 3^{\prime} \text { ). } \\
\text { Macro-macro ( How societal structure } \\
\text { affects the behavior of social systems- } \\
\text { link } 4 \text {, how organizational structure } \\
\text { affects the behavior of organzation-link } \\
4^{\prime} \text {, how societal structure affects the }\end{array}$ \\
\hline
\end{tabular}




\begin{tabular}{|c|c|c|c|}
\hline & Belief formations & Action formation & Outcome \\
\hline & & & $\begin{array}{l}\text { behavior of organzation }-\operatorname{link} 5 \text {, and } \\
\text { how organziational structure affects } \\
\text { the behavior of social systems- link } 5^{\prime} \text { ). }\end{array}$ \\
\hline Constructs & $\begin{array}{l}\text { Societal structure: Cultural or } \\
\text { normative patterns that define } \\
\text { expectations of agents about each } \\
\text { other's behavior and that organize } \\
\text { enduring interrelationships } .^{+} \\
\text {Organizational structure: Ways in } \\
\text { which an organization divides its } \\
\text { labor into distinct tasks and achieves } \\
\text { coordination among them. } .^{\ddagger} \\
\text { Psychic state: Beliefs, desires, } \\
\text { opportunities, etc. }\end{array}$ & $\begin{array}{l}\text { Action: Something done by } \\
\text { an individual, such as } \\
\text { adoption of an information } \\
\text { system to improve } \\
\text { organizational recycling or } \\
\text { facilitate ride sharing. }\end{array}$ & $\begin{array}{l}\text { Behavior of society: Functioning of } \\
\text { society and natural environment } \\
\text { (includes performance). } \\
\text { Behavior of organization: Functioning } \\
\text { of organization (includes } \\
\text { performance). }\end{array}$ \\
\hline $\begin{array}{l}\text { Example } \\
\text { studies }\end{array}$ & $\begin{array}{l}\text { Integrated assessment using a } \\
\text { designed information system } \\
\text { changed individual } \\
\text { beliefs about risks of } \\
\text { climate change } \\
\text { (Schlumpf et al. 2001). }\end{array}$ & $\begin{array}{l}\text { Belief that reducing } \\
\text { greenhouse gas emissions } \\
\text { is critical to sustainability } \\
\text { leads to adoption of } \\
\text { social networking site } \\
\text { encouraging } \\
\text { energy conservation (Bottrill } \\
\text { 2007). }\end{array}$ & $\begin{array}{l}\text { IT investment in } \\
\text { services and most } \\
\text { manufacturing sectors increases } \\
\text { electricity demand, with } \\
\text { implications for greenhouse } \\
\text { gas emissions (Cho et al. 2007). }\end{array}$ \\
\hline $\begin{array}{l}\text { Example } \\
\text { theories }\end{array}$ & $\begin{array}{l}\text { Contingency theory. } \\
\text { Information processing theory. } \\
\text { Media richness theory. }\end{array}$ & $\begin{array}{l}\text { Game theory. } \\
\text { Social cognitive theory. } \\
\text { Technology acceptance } \\
\text { model. } \\
\text { Theory of planned behavior. } \\
\text { Theory of reasoned action. }\end{array}$ & $\begin{array}{l}\text { Absorptive capacity. } \\
\text { Dynamic capability theory. } \\
\text { Production theory. } \\
\text { Resource-based theory. } \\
\text { Systems' theory. }\end{array}$ \\
\hline
\end{tabular}

${ }^{+}$Adapted from 47

‡ See 48

Table 2. BAO framework terminology. Source: Ref. 43

Finally, the framework is consistent with the study of dynamic change processes as well as static cross-sectional analysis. For example, the adoption of an environmental management system (EMS) incorporating an online social network with the goal of engaging employees, improving environmental performance, and reducing costs might be viewed as an organizational change process involving belief formation (links 1, 1'), sustainability actions (link 2), and environmental (link 3) and organizational performance (link 3') outcomes. In contrast, a survey of organizational use of IS for sustainability and perceived environmental performance impacts might focus entirely on the macro-macro (link 5') [43]. 


\section{Conclusions}

Being able to visualize the sustainable supply chain as a complex adaptive system helps us to avoid making mistakes, such as over-simplifying the problem, and to treat it as a deterministic case. This approach allows us to consider all the seemingly insoluble problems as they arise. Thinking of a supply chain that is sustainable requires a lot of effort in terms of not only theory and a change of paradigms but also as a practical undertaking, because as Pagell and Shevchenko [49] point out we need to avoid having supply chains that are merely less unsustainable while, at the same time, not being truly sustainable. In this study, we proposed gamedynamical replicator equations for multiple populations to describe the evolution in time of the proportions $p(t)$ and $q(t)$ of cooperative companies in populations 1 and 2 of the same supply chain. In the model, we assumed that companies in population 1 prefer to adopt sustainable management practices in their operations while companies in population 2 operate based on unsustainable management practices, but the companies of populations 1 and 2 interact in a daily basis interchanging material, information and capital flows. From our simulation results, we observed that the total success of cooperation depends on the payoffs resulting from interactions with companies that have adopted sustainable management. We suggest that government and institutions need to recognize and increase the benefits for prestigious companies in adopting the best sustainability principles and practices as their strategy, in order to contribute to their motivation for maintaining their reputation as contributors for local and global sustainable development. We conclude that sustainable management of supply chains needs to be studied as CASs, in order to take into account the social side of sustainability. Finally, the combined use of game theory and simulation by agents using an approach of complex adaptive systems led us to have a series of opportune activities that can be improved and broadened as they are put into practice by different businesses with a commitment to sustainability. In the words of Pagell and Shevchenko "If we continue to conduct research that mainly focuses on how variations on existing practices impact the ability of unsustainable supply chains to become less unsustainable, then we will miss a critical opportunity to lead future practice and the development of a new supply chain model.

\section{Author details}

Aida Huerta Barrientos* and Idalia Flores de la Mota

*Address all correspondence to: aida.huerta@comunidad.unam.mx

Department of Operations Research, Faculty of Engineering, National Autonomous Mexico University, Mexico City, Mexico 


\section{References}

[1] United Nations. Transforming our world: The 2030 Agenda for Sustainable Development (Resolution A/RES/70/1). 2015

[2] Amaeshi KM, Osuji OK, Nmodim P. Corporate social responsibility in supply chains of global brands: A boundaryless responsibility? Clarifications exceptions and implications. Journal of Business Ethics. 2008; 81; 223-234.

[3] Quariguasi J, Bloemhof-Ruwaard J. Designing and evaluating sustainable logistics networks. International Journal of Production Economics. 2008; 111; 195-208.

[4] Linto J, Klassen R, Jayaraman V. Sustainable supply chains: An introduction. Journal of Operations Management 2007; 25; 1075-1082.

[5] Cooper MC, Lambert DM, Pagh JD. Supply chain management: More than a new name for logistics. International Journal of Logistics Management 1997; 8; 1-13.

[6] Ahi P, Searcy C. A comparative literature analysis of definitions for green and sustainable supply chain management. Journal of Cleaner Production 2013; 52; 329-341.

[7] Carter RC, Rogers DS. A framework of sustainable supply chain management: Moving towards new theory. International Journal of Physical Distribution \& Logistics Management 2008; 135; 360-387.

[8] Seuring S, Muller M. From a literature review to a conceptual framework for sustainable supply chain management. Journal of Cleaner Production 2008; 16; 1699-1710.

[9] Wu Z, Pagell M. Balancing priorities: Decision-making in sustainable supply chain management. Journal of Operations Management 2011; 29; 577-590.

[10] Taticchi P, Garengo P, Nudurupati S, Tonelli F, Pasqualino R. A review of decisionsupport tools and performance measurement and sustainable supply chain management. International Journal of Production Research 2015; 53; 6473-6494.

[11] Beske P, Land A, Seuring S. Sustainable supply chain management practices and dynamic capabilities in the food industry: A critical analysis of the literature. International Journal of Production Economics. 2014; 152; 131-143.

[12] Dües CM, Tan KH, Lim M. Green as the new Lean: How to use Lean practices as a catalyst to greening your supply chain. Journal of Cleaner Production 2013; 40; 93-100.

[13] Boukherroub T, Ruiz A, Guinet A, Fondrevelle J. An integrated approach for sustainable supply chain planning. Computers \& Operations Research 2015; 54; 180-194.

[14] Brandenburg M, Rebs T. Sustainable supply chain management: A modelling perspective. Annals of Operations Research 2015; 229; 213-252.

[15] Seuring S. A review of modelling approaches for sustainable supply chain management. Decision Support Systems 2013; 54; 1513-1520. 
[16] Brandenburg M, Govindan K, Sarkis J, Seuring S. Quantitative models for sustainable chain management: Developments and directions. European Journal of Operational Research 2014; 233; 299-312.

[17] Sitek P, Wikarek J. A hybrid framework for the modelling and optimisation of decision problems in sustainable supply chain management. International Journal of Production Research 2015; 53; 6611-6628.

[18] Choi T, Dooley K, Rungtusanatham M. Supply networks and complex adaptive systems: Control versus emergence. Journal of Operations Management 2001; 19; 351366.

[19] Dunne J, Brose U, Williams R. Modeling food-web dynamics: Complexity-stability implications. 2004. Santa Fe Institute (SFI) working paper 2004-07-021.

[20] Bettencourta L, Cintrón-Arias A, Kaiser D, Castillo-Chávez C. The power of a good idea: Quantitative modelling of the spread of ideas from epidemiological models. Physica A 2006; 364; 513-536.

[21] Kimbrough S, Wu D, Zhong F. Computers play the beer game: Can artificial agents manage supply chains. Decision Support Systems 2002; 33; 323-333.

[22] Schianetz K, Kavanagh L. Sustainability indicators for tourism destinations: A complex adaptive systems approach using systemic indicator systems. Journal of Sustainable Tourism 2008; 16; 601-628.

[23] Walker B, Salt D. Resilience thinking: Sustaining ecosystems and people in a changing world. Washington, DC: Island Press. 2006. 192.

[24] Carpenter S, Walker B, Anderies JM, Abel N. From metaphor to measurement: Resilience of what to what? Ecosystems 2001; 4; 765-781.

[25] Hoof B, Thiell M. Collaboration capacity for sustainable supply chain management: Small and medium-sized enterprises in Mexico. Journal of Cleaner Production 2014; 67; 239-248.

[26] Auyang S. Foundations of complex-system. Theories in economics, evolutionary biology, and statistical physics. Cambridge: Cambridge University Press. 1999.

[27] Helbing D. The automation of society is next: How to survive the digital revolution. Version 1.0. 2015. DOI: 10.13140/RG.2.1.2681.1603.

[28] Helbing D, Jihansson A. Evolutionary dynamics of populations with conflicting interactions: Classification and analytical treatment considering asymmetry and power. Physical Review 2010; 81.

[29] von Neuman J, Morgenstern O. Theory of games and economic behaviour. Princeton: Princeton University. 1944.

[30] Axelrod R. The evolution of cooperation. New York: Basic Books, Inc., Publishers. 1984. 
[31] Helbing D. Social Self-Organization, Understanding Complex Systems. Berlin: Springer-Verlag. 2012. DOI: 10.1007/978-3-642-24004-1_10.

[32] Maynard J. Game theory and the evolution of fighting. In On Evolution. Edinburgh: Edinburgh University Press. 1972.

[33] Maynard J, Price G. The logic of animal conflict. Nature 1973; 246; 15-18.

[34] Taylor P, Jonker L. Evolutionarily stable strategies and game dynamics. Mathematical Biosciences 1978; 40; 145-156.

[35] Schuster P, Sigmund K. Replicator dynamics. Journal of Theoretical Biology 1983; 100; 533-538.

[36] Helbing D, Lozano S. Phase transitions to cooperation in the prisoner's dilemma. Physical Review E 2010; 81.

[37] Helbing D, Johansson A. Cooperation, norms, and revolutions: A unified gametheoretical approach. PLoS One 2010; 5. DOI: 10.1371/journal.pone.0012530.

[38] Wilensky U, Rand W. An introduction to agent-based modeling: Modeling natural, social, and engineered complex systems with NetLogo. Cambridge: MIT Press. 2015.

[39] Nair A, Yan T, Ro Y, Oke A, Chiles T, Lee S. How environmental innovations emerge and proliferate in supply networks: A complex adaptive systems perspective. Journal of Supply Chain Management 2016; 52.

[40] Alezander RD. The Biology of Moral Systems. New York: de Gruyter, 1987.

[41] Milinski M, Semmann D, Krambeck H. Reputation helps solve the 'tragedy of the commons'. Nature 2002; 415; 424-426.

[42] Watson R (Ed.), Boudreau MC, Chen A, Huber M. Green IS. Building sustainable business practices. In Watson RT (Ed.), Information Systems: A Global Text, 2008, Athens, GA: Global Text Project, pp. 1-17.

[43] Melville N. Information systems innovation for environmental sustainability. MIS Quarterly. 2010; 34; No. 1; 1-21.

[44] Hevner A, March S, Park J. Design science in information systems research. MIS Quarterly. 2004; 28; No. 1; 75-105.

[45] Sterman JD. System dynamics modeling: tools for learning in a complex world. California Management Review. 2001; 43; No. 4, 8-28.

[46] Coleman JS. Foundations of Social Theory (2nd ed.). Cambridge, MA: Harvard University Press. 1994.

[47] Lopez J, Scott J. Social Structure. Buckingham, England: Open University Press. 2000.

[48] Mintzberg H. The Structuring of Organizations. Englewood Cliffs, NJ: Prentice-Hall. 1979. 
[49] Pagell M, Shevchenko A. Why Research in Sustainable Supply Chain Management Should Have no Future. Journal of Supply Chain Management. 2014; 50;No.1, 44-55. 